Pilot Evaluation of the Stop, Breathe \& Think Mindfulness App for Student Clients on a College Counseling Center Waitlist 


\begin{abstract}
Objectives: College counseling centers face significant challenges meeting the mental health needs of their students and waitlists are common. Mobile apps offer a promising solution to increase access to resources while students wait for services. Methods: This pilot randomized controlled trial evaluated the feasibility and acceptability of a publicly available mindfulness app. Students on a counseling center waitlist $(n=23)$ were randomized to use the app or not, with assessments completed over four weeks. Results: Recruitment over three semesters was slow, leading to an underpowered trial. Participants reported high satisfaction and moderate app usage. Very preliminary support was found for potential app efficacy relative to the control condition, particularly for depression, anxiety, and overall distress. Weaker, mixed effects were found for mindfulness and values processes. Conclusions: Overall, these results provide mixed findings suggesting the potential benefits, but also challenges in using a mindfulness app for students waiting to receive counseling services.
\end{abstract}

Keywords: Mindfulness, mHealth, eHealth, Online, College Students. 


\section{Pilot Evaluation of the Stop, Breathe \& Think Mindfulness App for Student Clients on a College Counseling Center Waitlist}

College counseling centers experience significant challenges with meeting the mental health needs of their college students. Mental health problems are highly prevalent among college students. ${ }^{1,2}$ For example, the 2018 National College Health Assessment found at some point in a given year the majority of college students feel overwhelmed (86\%), very sad (69\%), very lonely (65\%), overwhelming anxiety (63\%), and hopeless (55\%), with $13 \%$ seriously considering suicide. ${ }^{1}$ Research indicates that the prevalence and severity of mental health problems among college students is rising as well as the rate of treatment seeking. ${ }^{3-5}$ Yet, college counseling center staffing has not grown to match this increase in demands, with approximately 1 counselor for every 2,081 students. $^{3}$

A number of methods are being employed to address the discrepancy between the demand for treatment and supply of service resources, but some form of waiting to start treatment is still common. ${ }^{3,6}$ In one national survey, $34 \%$ of centers reported having a formal waitlist, but across all clients the average wait time before first appointment was 6.7 business days, indicating some notable waiting time occurs for most clients. ${ }^{6}$ These waiting times represent a gap in services that could be addressed with innovative, efficient solutions.

Mobile apps provide a promising solution to increase mental health resources for clients waiting to begin counseling, without placing significant additional resource costs on centers. There is a growing body of evidence supporting the efficacy of mobile apps to improve mental health in general $^{7}$ as well as among college students specifically. ${ }^{8,9}$ A mobile app can teach evidence-based strategies in a self-guided format to improve mental health concerns for 
waitlisted students, potentially preventing a worsening of concerns, reducing current suffering, and preparing them for therapy.

Most college counseling centers report using mobile technology in some manner (e.g., health information, intervention ${ }^{10}$ ), but to the best of our knowledge only one study has evaluated mobile apps for students waiting for counseling center services. This small open trial of a prototype mobile app teaching skills from acceptance and commitment therapy (ACT) in waitlisted students found significant decreases in depression, anxiety, and stress over two weeks, in addition to high acceptability. ${ }^{11}$ Although this pilot found positive results, it used a prototype app that is not readily available to counseling centers. Studies are needed to evaluate publicly available apps that counseling centers can, or may already be recommending to clients waiting for services.

Mindfulness apps may be particularly well-suited for waitlisted students. Mindfulness interventions involves learning how to flexibly attend to experiences in the present moment in a way that is nonjudgmental and nonreactive. Mindfulness-based therapies when delivered inperson have been found effective for a wide range of mental health concerns including depression, anxiety disorders, eating disorders, and substance abuse, ${ }^{12-14}$ which is advantageous given the range of presenting problems students seeking help may have. ${ }^{6}$ Mindfulness has also been found effective meta-analyses relative to other active treatments including treatment as usual $(g=.44)$, psychoeducation $(g=.61)$, and supportive therapy $(g=.37)$, and equivalent to cognitive behavioral therapies $(g=-.07) .{ }^{12}$ In addition to efficacy, a review of mediational analyses found empirical support for theorized mechanisms of change for mindfulness including increased mindfulness skills, decreased repetitive negative thinking (e.g., rumination, worry), decreased cognitive/emotional reactivity, and increased self-compassion. ${ }^{15}$ 
Research indicates that mindfulness is similarly effective when delivered in self-guided formats without concurrent in-person treatment. ${ }^{16}$ A recent, growing body of research has further found support for the efficacy of mindfulness mobile apps specifically, ${ }^{17}$ including with college students. ${ }^{18-21}$ For example, 208 college students were randomized to one of two publicly available mindfulness apps (Headspace or Smiling Mind) or a control group (Evernote), with results indicating significant improvements in depression over 10 days for the mindfulness apps relative to control condition. ${ }^{18}$ Support was also found for underlying processes of change with Headspace increasing self-reported mindfulness relative to control and mindfulness app usage predicting maintenance of mental health improvements over time. ${ }^{18}$ Similarly, a study randomized 88 college students reporting high stress to the Calm mindfulness app (publicly available) or a waitlist, with results indicating significant improvements in stress, mindfulness, and self-compassion over 8-weeks for the mindfulness app relative to waitlist. ${ }^{19}$

Another publicly available mindfulness app that has received minimal direct research todate is Stop, Breathe \& Think (https://www.stopbreathethink.com/). In addition to providing a library of mindfulness exercises, the Stop, Breathe \& Think app assesses users' emotional state at the start of a session, to guide suggestions for mindfulness exercises, and after completing an exercise. Stop, Breathe \& Think has not been tested in a randomized controlled trial, but a naturalistic study examined changes in emotional states among 120,000 app users. ${ }^{22}$ Results indicated significant improvements in emotional states over time, with longer app usage predicting greater improvements.

Although there are initial studies supporting the efficacy of mindfulness apps as a selfguided resource for college students, ${ }^{18-21}$ there appears to be no research into whether mindfulness apps may benefit those waiting for treatment. In addition to their potential efficacy, 
mindfulness apps are among the most common mental health apps, ${ }^{23}$ available at low or no cost ${ }^{24}$ and initial evidence suggests therapists using mindfulness apps find them useful when working with their clients. ${ }^{25}$ Thus, mindfulness apps may be ideal for use in counseling center waitlists, but this has yet to be empirically tested. If mindfulness apps are acceptable to students waiting for treatment and using such apps results in improved mental health, it would indicate that mindfulness apps could be used to help meet crucial mental health needs on campus without placing a significant additional burden onto college counseling centers.

The current pilot randomized controlled trial sought to evaluate the feasibility and acceptability of a popular mindfulness meditation app (Stop, Breathe \& Think) for students on a college counseling center waitlist. The mindfulness app was compared to a condition in which students received no additional resources, with assessment completed 2- and 4-weeks after baseline. This study predicted that the mindfulness app would be acceptable to waitlisted students as indicated by high self-reported satisfaction and app usage. The study also predicted the mindfulness app would result in greater improvements in mental health and mindfulness relative to those who did not receive the app.

\section{Method}

\section{Participants}

The final sample consisted of 23 university students on the waitlist for the Counseling and Psychological Services center (CAPS) at a university in the Mountain West region of the United States. Study inclusion criteria were 1) 18 years of age or older, 2) owning a smartphone (Android or iPhone), 3) current student at the university, and 4) currently seeking treatment at CAPS with an expected wait time of at least two weeks for services. Recruitment occurred over three semesters from January 2018 to March 2019. Participants were primarily recruited through 
flyers provided at CAPS by counseling center staff. Initially, 44 individuals were screened for eligibility, but 21 were identified as ineligible, with the remaining 23 participants completing the baseline assessment and being randomized to either the SBT $(n=10)$ or control conditions $(n=$ 13; see Figure 1).

\section{Procedures}

This study was approved by the authors' Institutional Review Board and all participants provided informed consent prior to participating. Participants completed online assessments at three time points: a baseline survey, a mid-intervention survey ( 2 weeks after baseline), and a post-intervention survey ( 4 weeks after baseline). The mid-intervention assessment corresponded to the expected 2-week waiting period before seeing a counselor, with the post-intervention assessment corresponding to an expected 2-weeks of receiving therapy from a counselor.

After participants completed the first baseline survey, they were randomized to either use the Stop, Breathe, and Think mindfulness app right away for four weeks (SBT condition) or to wait for four weeks without receiving additional resources (Control condition). Randomization was conducted automatically through Qualtrics immediately after completing baseline, with a 1:1 allocation ratio in blocks of 10 (to ensure equal sample sizes over time). Those assigned to the SBT condition, were asked to download the app onto their smartphone to use daily over four weeks. Participants in the Control condition received instructions on how to download the SBT app after completing the final post-intervention survey.

\section{Intervention}

Stop, Breathe, and Think is a free app with the option of purchasing a premium version for access to additional guided meditation content. Participants were instructed to just use the free version of the app. When the app is opened, there is an option to complete a brief check-in 
assessment, which asks the user to rate how they are doing physically and mentally, with a "great", "good", "meh", "poor", or "rough" rating scale. The assessment then asks about how the user is doing emotionally, offering an extensive list of emotions to choose from. The result of the assessment is a short list of tailored meditation options based on the results. Alternatively, there is also an option for the user to skip the check-in assessment and go straight to the full list of guided meditations contained in the app.

The full list of meditations includes collections of meditations based on a theme (e.g. "Get Started," "Sleep Well," "Tame Your Anxiety," "Find Your Calm," "Connect With Your Body”) as well as the option to browse all exercises. Guided meditations include breathing meditations, body scan mediations, mindful walking exercises, loving-kindness focused meditations, mindfulness of sounds, mindfulness of sensations, gratitude mindfulness and mindfulness of other positive experiences, and grounding mindfulness exercises. These meditations covered a wide range of mindfulness procedures engaging a similarly broad range of mindfulness-related processes (e.g., observing, describing, cognitive decentering, being nonjudgmental, acceptance, emotion regulation). The guided exercises generally range from one to ten minutes, with most being in the three to seven minutes range. After a meditation exercise is completed, the user is prompted to choose one of three options: to complete another brief assessment check-in, to view their meditation progress, or to complete another exercise; they can also select "finish" instead of choosing one of the three options. The mobile app also included self-guided instructions to learn more about mindfulness and how to develop a mindfulness practice.

The app also monitors the user's progress via current and "all-time" daily streaks, meaning the number of days in a row the user has checked-in or completed a meditation 
exercise. It also tracks the user's mental and physical check-ins before and after meditations, the user's “top emotions" before and after meditations, the user's top meditation exercise choice, and the user's total time spent meditating with the app. Additionally, engagement with the app in the form of check-in assessments and completing meditations results in receiving "stickers" to reinforce app engagement.

\section{Measures}

\section{Counseling Center Assessment of Psychological Symptoms-34 item version}

(CCAPS-34 $\left.{ }^{26}\right)$. The CCAPS is the gold-standard measure for mental health symptoms among college counseling centers and was used as the primary outcome for this study. The 34-item version of the CCAPS includes an overall distress score as well as subscales for depression, general anxiety, social anxiety, academic distress, eating concerns, hostility, and alcohol use. Thirty-four items are rated on a 5-point scale, with higher numbers indicating higher levels of distress or concern. The CCAPS has been found to have good reliability and validity in previous studies with both non-clinical and distressed college students. ${ }^{26}$

Mental Health Continuum - Short Form (MHC-SF $\left.{ }^{27}\right)$. The MHC-SF was included as a secondary outcome measure of positive mental health. The MHC-SF assesses emotional wellbeing, psychological well-being, and social well-being. ${ }^{27}$ The MHC-SF uses a 6-point scale, with higher scores indicating more positive mental health. The MHC-SF has been shown to have good validity and reliability with a variety of samples $\left(e . g .^{27,28}\right)$.

Five Facet Mindfulness Questionnaire (FFMQ ${ }^{29}$ ). The FFMQ was used as the primary process of change measure. The FFMQ is a 39-item measure of mindfulness that assesses five key facets of the construct: Observing, Describing, Acting with awareness, Nonjudging of inner experiences, and Nonreactivity to inner experiences. Each item is rated on a 5-point scale. The 
FFMQ has demonstrated good validity and reliability with college student samples, although with mixed results for the observing subscale. ${ }^{29}$

Valuing Questionnaire $\left(\mathbf{V} \mathbf{Q}^{\mathbf{3 0}}\right)$. The VQ was included as a secondary process measure. The VQ measures valued action, a construct from the broader acceptance and mindfulness-based therapy literature that refers to behaving consistently with what is deeply meaningful and important to oneself. The 10-item VQ includes two subscales assessing values progress (i.e., actions consistent with personal values) and values obstruction (i.e., difficulty engaging in valued action). Each item is rated on a 7-point scale. The VQ has been found to have good reliability and validity including among college students. ${ }^{30}$

System Usability Scale (SUS ${ }^{\mathbf{3 1}}$ ). The SUS measures program usability and acceptability with 10 items rated on a 5-point scale. An analysis of studies using the SUS found that it demonstrated strong reliability and validity. ${ }^{32}$ Additional items were adapted from prior studies to assess aspects of program satisfaction such as helpfulness, ease of use, perceived fit, and similar dimensions. ${ }^{11}$ These items were rated on a 6-point scale with 4 (slightly agree) or higher indicating a positive response.

Program Usage. Participants self-reported how many days they used the app in the past two weeks. Participants also reported their program usage data from the Stop, Breathe, and Think app, including their total time spent meditating and their "daily streaks," which is automatically tracked in the app and viewable through a user dashboard.

\section{Results}

\section{Participant Flow and Missing Data}

A participant flow chart is provided in Figure 1. Over the three semesters planned for recruitment (Spring 2018, Fall 2018, Spring 2019) only 23 participants were enrolled into the 
study, with the majority enrolling in the Fall 2018 semester $(n=17)$. Of note, 21 participants were screened ineligible, with 17 due to not being a college student or on the waitlist at CAPS (and thus likely having come from non-CAPS sources to the lab website signup page). This suggests a low response rate among college students at CAPS, which raises feasibility and acceptability concerns.

With regards to missing data, $83 \%$ of participants $(n=19)$ completed the mid-intervention assessment and $70 \%$ completed the post-intervention assessment $(n=16)$. Missing data rates were equivalent between conditions $(p>.10)$. Due to the sample size, rate of missing data, and focus on descriptive analyses, a listwise deletion approach was used for each analysis (i.e., each analysis only included participants with necessary available data).

\section{Participant Characteristics and Preliminary Analyses}

Consistent with the expected timing of assessments, only $11 \%$ of participants reported any in-person treatment sessions over the past 2-weeks at mid-intervention assessment (in both cases only receiving one session thus far). However, at post-intervention assessment when participants were expected to have started in-person therapy, only $19 \%$ reported any in-person treatment sessions over the past 2-weeks (in each case receiving two therapy sessions). Thus, both the midand post-intervention time points largely represent participants who had not yet received counseling services.

Participants ranged in age from 18 to $25(M=20.43$ years, $S D=2.46$ years $)$. The sample was $100 \%$ female and $87 \%$ non-Hispanic, White (with 9\% Hispanic, White and 4\% American Indian and White). Based on the Counseling Center Assessment of Psychological Symptoms (CCAPS$\left.34^{19}\right), 96 \%$ of the sample met the lower cutoff on the CCAPS distress index, indicating some degree of distress, and 52\% met the elevated cutoff. In terms of specific CCAPS problem areas, 
$70 \%$ were elevated on depression, $57 \%$ on general anxiety, $57 \%$ social anxiety, $52 \%$ academic distress, $44 \%$ eating concerns, $17 \%$ hostility, and 9\% alcohol use. Participants indicated an interest in self-help mobile apps at baseline using a 7-point scale with 5 (slightly agree) or higher indicating interest: "I would personally benefit from using a self-help mobile app like the one being tested in this study" $(M=5.17, S D=1.15,65 \% \geq 4$ "slightly agree") and "I am interested in using a self-help mobile app" $(M=5.43, S D=1.16,78 \% \geq 4)$. Demographics are listed by condition in Table 1. There were no differences at baseline between conditions on outcomes, processes of change, or demographics $(p>.05)$.

Descriptive statistics and distributions were checked for each dependent variable. Of note, $74 \%$ scored 0 on the CCAPS alcohol subscale and $0 \%$ were elevated on the alcohol subscale in the SBT condition. This is consistent with the specific University student population, which predominantly belongs to a religion that prohibits alcohol use. The alcohol subscale was thus excluded from analyses.

\section{Program Satisfaction}

Descriptive statistics were examined among the 6 participants in the SBT condition who completed the post-intervention self-report assessment. On average, participants provided a usability score of 77.00 on the SUS $(S D=16.71)$. A score of 77 is in the "good" range, ${ }^{25}$ and slightly lower, but within $1 S D$, of SUS scores found for similar acceptance and mindfulnessbased apps evaluated with college students (e.g., ${ }^{11,33}$ ).

Individual satisfaction items were rated on a 6-point scale, with 4 (slightly agree) or higher indicating a positive response (see Table 2). Participants gave moderately positive ratings for the app on various dimensions of satisfaction including perceived helpfulness, ease of use, and fit. Participants agreed in general that the app would be helpful for those on the waitlist, that they did 
not need more training to use the app, and that the app increased motivation to see a therapist. That said, all participants would have preferred to see a therapist right away instead, and disagreed that the app was helpful enough that they did not need to see a therapist. Participants generally disagreed that the app would be a good replacement for seeing a therapist, and agreed the app would be more helpful if used while actively seeing a therapist.

\section{Program Usage}

Program usage data was derived from self-report with instructions to review the app dashboard that collected app usage data automatically. Among the 8 SBT participants reporting app usage at mid-intervention assessment, they self-reported using the app on 7.44 days on average $(S D=3.87)$, with $63 \%$ using the app 7 or more days and $100 \%$ using the app at least once. Total time meditating over the first two weeks was 40.66 minutes on average $(S D=31.29)$. Among the 5 participants reporting app usage at post, usage dropped to 5.80 days on average over the past two weeks $(S D=5.32)$, with $40 \%$ using the app 7 or more days and $20 \%$ not using the app at all. Total meditation over the entire 4 weeks was 89.20 minutes on average $(S D=$ 58.17).

A subsample of 4 SBT participants self-reported reasons for not using the app at postintervention. The most frequent reasons were forgetting to use the app $(n=3)$, not having time $(n$ $=3)$, not feeling comfortable using the app around others $(n=2)$, and not seeming helpful $(n=$ 1).

\section{Mental Health Outcomes}

Due to the small sample size obtained in this pilot study, a descriptive approach was taken to examining effect sizes along with reporting $90 \%$ confidence intervals consistent with recommendations for reporting pilot results. ${ }^{34}$ Hedge's $g$ effect sizes and $90 \%$ confidence 
intervals were calculated between conditions from pre- to mid-intervention and pre- to postintervention (see Table 3). Effect sizes were calculated using a listwise deletion approach for missing data: pre- to mid-intervention ( $\operatorname{SBT} n=8$, Control $n=11$ ) and pre- to post-intervention effects (SBT $n=6$, Control $n=10)$.

Large effect sizes for SBT were found from pre- to mid-intervention between the SBT and control conditions on overall distress, depression, general anxiety, and hostility, with 90\% confidence intervals not including zero and generally ranging from small to large favoring SBT. Small effect sizes from pre- to mid-intervention were found favoring SBT for academic concern and eating concerns, but with $90 \%$ confidence intervals ranging from small negative effects favoring the control condition to large effects favoring the SBT app. The effect size for social anxiety was approaching zero $(\mathrm{g}=.11)$ and a small negative effect size favoring the control condition was found for positive mental health.

Large effect sizes were found for SBT from pre- to post-intervention for overall distress and depression, with $90 \%$ confidence intervals ranging from near (but above) zero to large effects favoring SBT. Small to medium effect sizes from pre- to post-intervention favoring SBT were found for general anxiety, social anxiety, hostility, academic concerns, eating concerns, and positive mental health, but with $90 \%$ confidence intervals ranging from small negative effects favoring the control condition to large effects favoring SBT.

\section{Process of Change Analyses}

Hedge's $g$ effect sizes and $90 \%$ confidence intervals were also calculated for process of change measures between conditions from pre- to mid-intervention and pre- to post-intervention (see Table 3). A large effect size was found from pre- to mid-intervention for acting with awareness, with the $90 \%$ confidence interval ranging from a small to large effect size favoring 
SBT. Small to medium effect sizes were found from pre- to mid-intervention for describing, nonjudging, and values obstruction, but with confidence intervals ranging from small negative effects favoring the control to large effects favoring SBT. Negative small to medium effect sizes were surprisingly found for observing, nonreacting, and values progress from pre- to midintervention favoring the control condition, with confidence intervals generally ranging from a large negative effect favoring the control condition, to a near zero effect favoring SBT.

A large effect size was found from pre- to post-intervention for values progress, with the confidence interval ranging from a near zero negative effect, to a large effect favoring SBT. Small to medium effects were found from pre- to post-intervention for observing, describing, acting with awareness, nonjudgmental, and values obstruction, with confidence intervals generally ranging from a small negative effect favoring control to a large effect favoring SBT. A negative effect favoring control was found from pre- to post-intervention for nonreacting, with the confidence interval ranging between a large negative effect favoring control to a medium effect favoring SBT.

\section{Discussion}

This study sought to conduct the first pilot randomized controlled trial evaluating the feasibility and acceptability of a widely available mindfulness app (Stop, Breathe and Think) for college students waiting to receive services at a college counseling center. Consistent with predictions, participants provided high satisfaction ratings with the app and reported regularly use of the app, particularly in the first two weeks. However, the rate of recruitment was slow over three semesters, suggesting a low response rate that indicates acceptability and feasibility concerns. Due to the small recruited sample, a descriptive approach to reporting effect sizes with more liberal confidence intervals was used. These results provided very preliminary support for 
the potential efficacy of the SBT app, particularly for depression, anxiety, and general distress. Effect sizes were weaker and more mixed on mindfulness and values processes of change, although they still generally favored the SBT condition, especially at post-intervention. Overall, these results provide mixed findings suggesting the potential benefits, but also challenges in using a mindfulness app for students waiting to receive counseling services.

College counseling centers face significant challenges in meeting the prevalent, growing mental health needs of their students with the limited resources available. Mobile apps and related technologies are promising in helping address current service gaps and increase mental health resources without overburdening already taxed centers, but apps also introduce their own set of challenges. ${ }^{35}$ This study highlighted some of the barriers that need to be addressed in order to meet the potential promise of mobile apps.

The students who did enroll in the study were satisfied with and reported using the app. However, the response rate was low and students who did enroll were notably more enthusiastic about using a mobile app than previous college student surveys would indicate (e.g., $\left.{ }^{36}\right)$. This suggests offering a mobile app for waitlisted students may only be of interest to a select subsample. This is consistent with past surveys of students regarding interests in mobile apps versus in-person resources ${ }^{36}$ as well as a previous trial that also found a low response rate when testing a mobile app for waitlisted students. ${ }^{11}$ Of note, participants reported a preference to have instead used the app during therapy, rather than while on the waitlist, which has also been found in other surveys of both students ${ }^{36}$ and therapists. ${ }^{25}$ It is thus unclear if the target should be increasing interest in using apps while on the waitlist or identifying the subgroup interested in using an app on the waitlist, recognizing this is a more limited solution and other students might not use apps until starting counseling. There are other barriers that might have also reduced 
response rate including the research components that might have made enrollment less enticing or more burdensome as well as some counselors and staff potentially not providing recruitment information to all relevant students. Previous research testing online interventions with college students actively meeting with a therapist found low response rates that were likely due at least in part to counselors not inviting relevant clients. ${ }^{37}$ Thus, the barriers to implementing these technologies are likely complex, multifaceted, and needing additional research and innovative solutions.

This study was innovative in evaluating a publicly available mobile app that is regularly used by and recommended to college students. Much of the existing research has focused on evaluating prototype apps developed for a research study and not publicly available, leading to a gap between apps known to be efficacious in research and apps that are popularly among students and counselors. ${ }^{7}$ With the ever growing number of apps developed, not every one can be evaluated. However, it is critical that at least some of the most widely used and recommended mobile apps be tested to confirm their efficacy and inform evidence-based recommendations to clients.

The current study found very preliminary support suggesting the Stop, Breathe and Think mindfulness app might improve mental health among students waiting for counseling services. Large positive effects were found over time for the SBT condition relative to the control condition on distress, depression, anxiety, and hostility, with confidence intervals suggesting effect sizes likely fall within a small to large range favoring SBT. Weaker, but still positive effects, were generally found for other mental health outcomes. That said, results are based on a descriptive approach and liberal confidence intervals due to the low sample size enrolled in the pilot study. Thus, these findings should be interpreted with caution as an initial "signal" that 
requires replication with a larger sample and appropriate methodological controls. If results replicated, they could guide evidence-based recommendations for using Stop, Breathe and Think (a publicly available and widely used app) with clients on counseling center waitlists.

Findings from this pilot trial also identified feasibility challenges that would need to be addressed in a future confirmatory efficacy trial. Most notably, future research will need to overcome recruitment challenges, which were likely due to a combination of factors including acceptability to student clients and engagement from counselors and staff recruiting participants.

A related issue was that most participants reported not yet starting in-person therapy four weeks after enrolling in the study. It is unclear whether this is due to participant choice (e.g., improving sufficiently on their own such that they no longer sought treatment), access to treatment (e.g., longer than expected waitlists at the counseling center), missing data (e.g., participants who started therapy did not complete later assessments), or a combination of these factors. In any case, this further highlights the potential need for self-guided resources that students can access while waiting to begin counseling, while also identifying feasibility issues for studying the effects of such apps for waitlisted clients. Future studies would benefit from integrating research more actively within counseling centers to clarify how these resources interact with and affect counseling services (e.g., effects of app assignment on subsequent participation in treatment, clarifying when participants begin in-person counseling or why inperson counseling is never initiated).

As a pilot evaluation of a publicly available app this study had notable limitations. There was limited power due to a low response rate over three semesters of recruitment. Consistent with recommendations for pilot research, ${ }^{34}$ a descriptive approach to reporting effect sizes with a more liberal $90 \%$ confidence interval was used, which should be interpreted with notable caution 
given the potential for Type I error. In addition, the sample was homogenous in terms of gender, race/ethnicity, and university, which limits generalizability of results. The study was also limited in that app usage was measured by self-report rather than objective data tracking, which has been found to be less accurate. ${ }^{38}$ This was a necessary limitation due to the use of a publicly available app, but resulting usage findings should be interpreted with caution given the potential biasing from self-report. Feasibility and acceptability data were also limited due to the focus on quantitative assessment methods. Qualitative and formative evaluation steps would have helped to further clarify the barriers and facilitators to using a mindfulness mobile app with counseling center clients (e.g., focused interviews with clients or counselors).

Overall, this study provides the first pilot randomized controlled evaluation of the Stop, Breathe and Think mobile app and of any mobile app for college students waiting for counseling services. Given the challenges faced by counseling centers and the opportunities mobile apps afford, it is critical that research continue to research the efficacy of apps and how to effectively implement them to meet the mental health needs of college students. 


\section{References}

1. American College Health Association. American College Health Association-National College Health Assessment II: Undergraduate Student Executive Summary Fall 2018. Silver Spring, MD: American College Health Association; 2018.

2. Blanco C, Okuda M, Wright C, Hasin DS, Grant BF, Liu S-M, Olfson M. Mental health of college students and their non-college-attending peers. Archives of General Psychiatry. 2008;65(1429).

3. Gallagher R P. National Survey of College Counseling Centers 2014. Project Report. The International Association of Counseling Services (IACS). 2015.

4. Lipson S K, Lattie E G, Eisenberg, D. Increased rates of mental health service utilization by US college students: 10-year population-level trends (2007-2017). Psychiatric Services. 2018;70:60-63.

5. Xiao H, Carney D M, Youn S J, Janis R A, Castonguay L G, Hayes J A, Locke B D. Are we in crisis? National mental health and treatment trends in college counseling centers. Psychological Services. 2017;14:407-415.

6. LeViness P, Bershad C, Gorman K. The Association for University and College Counseling Center Directors annual survey. 2017. Retrieved from https://www.aucccd.org/directorsurveys-public

7. Torous J B, Levin M E, Ahern D, Oser M. Cognitive behavioral mobile applications: Research literature, marketplace data, and evaluation guidelines. Cognitive and Behavioral Practice. $2017 ; 24: 215-225$.

8. Harrer M, Adam S H, Fleischmann R J, Baumeister H, Auerbach R, Bruffaerts R, ... Ebert D D. Effectiveness of an internet- and app-based intervention for college students with 
elevated stress: Randomized controlled trial. Journal of Medical Internet Research. 2018;20:1-16.

9. Lee R A, Jung M E. Evaluation of an mhealth app (DeStressify) on university students' mental health: Pilot trial. Journal of Medical Internet Research Mental Health. 2018;5(e2).

10. Johnson K F, Kalkbrenner M T. The utilization of technological innovations to support college student mental health: Mobile health communication. Journal of Technology in Human Services. 2017;35:314-339.

11. Citation Removed for Blinding

12. Khoury B, Lecomte T, Fortin G, Masse M, Therien P, Bouchard V, ... Hofmann S G. Mindfulness-based therapy: A comprehensive meta-analysis. Clinical Psychology Review. 2013;33(6):763-771.

13. Turgon R, Ruffault A, Juneau C, Blatier C, Shankland R. Eating disorder treatment: A systematic review and meta-analysis of the efficacy of mindfulness-based programs. Mindfulness. 2019;10:2225-2244.

14. Chiesa A, Serretti A. Are mindfulness-based interventions effective for substance use disorders? A systematic review of the evidence. Subst Use Misuse. 2014;49:492-512.

15. Gu J, Strauss C, Bond R, Cavanagh K. How do mindfulness-based cognitive therapy and mindfulness-basedstress reduction improve mental health and wellbeing? A systematicreview and meta-analysis of mediation studies. Clinical Psychology Review. 201;37:1-12.

16. Cavanagh K, Strauss C, Forder L, Jones F. Can mindfulness and acceptance be learnt by selfhelp?: a systematic review and meta-analysis of mindfulness and acceptance-based selfhelp interventions. Clinical Psychology Review. 2014;34:118-129. 
17. Linardon J. Can acceptance, mindfulness, and self-compassion be learnt by smartphone apps? A systematic and meta-analytic review of randomized controlled trials. Behavior Therapy. In Press.

18. Flett J A M, Hayne H, Riordan B C, Thompson L M, Conner T S. Mobile mindfulness meditation: A randomised controlled trial of the effect of two popular apps on mental health. Mindfulness. 2019;10:863-876.

19. Huberty J, Green J, Glissmann C, Larkey L, Puzia M, Lee C. Efficacy of the mindfulness meditation mobile app "Calm” to reduce stress among college students: Randomized controlled trial. JMIR mHealth and uHealth. 2019;7: e14273.

20. Walsh KM, Saab BJ, Farb NA. Effects of a mindfulness meditation app on subjective wellbeing: Active randomized controlled trial and experience sampling study. JMIR Ment Health. 2019;6:e10844.

21. Moffitt-Carney KM, Duncan AB. Evaluation of a mindfulness-based mobile application with college students: A pilot study. J Am Coll Health. In Press.

22. Athanas AJ, McCorrison JM, Smalley S, Price J, Grady J, Campistron J, Schork NJ. Association between improvement in baseline mood and long-term use of a mindfulness and meditation app: Observational study. JMIR Ment Health. 2019;6:e12617.

23. West J H, Hall P C, Hanson C L, Barnes M D, Giraud-Carrier C, Barrett J. There's an app for that: Content analysis of paid health and fitness apps. Journal of Medical Internet Research. 2012;14(e72).

24. Mani M, Kavanagh D J, Hides, L, Stoyanov S R. Review and evaluation of mindfulnessbased iPhone apps. JMIR MHealth and UHealth. 2015;3(e82). 
25. Pierce B, Twohig M, Levin M E. Perspectives on the use of Acceptance and Commitment Therapy related apps: Results from a survey of students and professionals. Journal of Contextual Behavioral Science. 2016;5:215-224.

26. Center for Collegiate Mental Health. CCAPS 2012 technical manual. University Park, PA: CCMH; 2012.

27. Keyes C L M, Wissing M, Potgieter J P, Temane M, Kruger A, van Rooy S. Evaluation of the mental health continuum-short form (MHC-SF) in Setswana-speaking South Africans. Clinical Psychology \& Psychotherapy. 2008;15:181-192.

28. Lamers S M A, Westerhof G J, Bohlmeijer E T, ten Klooster P M, \& Keyes C L M. Evaluating the psychometric properties of the mental health Continuum-Short Form (MHC-SF). Journal of Clinical Psychology. 2011;67:99-110.

29. Baer R A, Hopkins J, Krietemeyer J, Smith G T, Toney L. Using Self-Report Assessment Methods to Explore Facets of Mindfulness. Assessment. 2006;13:27-45.

30. Smout M F, Davies M, Burns N, Christie A. Evaluating acceptance and commitment therapy: Development of the valuing questionnaire. Journal of Contextual Behavioral Science. 2014;3:164-172.

31. Brooke J. SUS: a "quick and dirty ee usability scale. In PW Jordan, B Thomas, BA Weerdmeester, and IL McClelland (Eds.) Usability Evaluation in Industry (189-194). London: Taylor and Francis; 1996.

32. Bangor A, Kortum P T, Miller J T. An empirical evaluation of the System Usability Scale. International Journal of Human-Computer Interaction. 2008;24:574-594. 
33. Levin M E, Haeger J, An W, Twohig M P. Comparing cognitive defusion and cognitive restructuring delivered through a mobile app for individuals high in self-criticism. Cognitive Therapy and Research. 2018;42:844-855.

34. Lee EC, Whitehead AL, Jacques RM, Julious SA. The statistical interpretation of pilot trials: Should significance thresholds be reconsidered? BMC Medical Research Methodology. 2014;14:41.

35. Lattie E G, Lipson S K, Eisenberg D. Technology and college student mental health: Challenges and opportunities. Frontiers in Psychiatry. In Press.

36. Levin M E, Stocke K, Pierce B, Levin C. Do college students use online self-help? A survey of intentions and use of mental health resources. Journal of College Student Psychotherapy. 2018;32:181-198.

37. Levin M E, Pistorello J, Hayes S C, Seeley J R, Levin C. Feasibility of an Acceptance and Commitment Therapy adjunctive web-based program for counseling centers. Journal of Counseling Psychology. 2015;62: 529-536.

38. Flett JAM, Fletcher BD, Riordan BC, Patterson T, Hayne H, Conner TS. The peril of selfreported adherence in digital interventions: A brief example. Internet Interventions. $2019 ; 18: 100267$. 
Table 1. Participant baseline demographics by condition.

\begin{tabular}{|c|c|c|}
\hline & $\begin{array}{l}\text { SBT App Condition } \\
M(S D) \text { or } \%\end{array}$ & $\begin{array}{l}\text { Control Condition } \\
M(S D) \text { or } \%\end{array}$ \\
\hline Age & $19.90(2.18)$ & $20.85(2.67)$ \\
\hline$\%$ Female & $100 \%$ & $100 \%$ \\
\hline \multicolumn{3}{|l|}{ Ethnicity } \\
\hline Hispanic/Latinx & $10 \%$ & $8 \%$ \\
\hline Not Hispanic/Latinx & $90 \%$ & $92 \%$ \\
\hline \multicolumn{3}{|l|}{ Race } \\
\hline White & $100 \%$ & $100 \%$ \\
\hline Asian & $0 \%$ & $0 \%$ \\
\hline Black/African American & $0 \%$ & $0 \%$ \\
\hline American Indian/Alaska Native & $10 \%$ & $0 \%$ \\
\hline Native Hawaiian/Pacific Islander & $0 \%$ & $0 \%$ \\
\hline Other & $0 \%$ & $0 \%$ \\
\hline \multicolumn{3}{|l|}{ Elevated on CCAPS ${ }^{a}$} \\
\hline Overall distress & $70 \%$ & $38 \%$ \\
\hline Depression & $90 \%$ & $54 \%$ \\
\hline General anxiety & $50 \%$ & $62 \%$ \\
\hline Social anxiety & $50 \%$ & $62 \%$ \\
\hline Academic concerns & $70 \%$ & $38 \%$ \\
\hline Eating concerns & $50 \%$ & $38 \%$ \\
\hline Hostility & $30 \%$ & $8 \%$ \\
\hline Alcohol use & $0 \%$ & $15 \%$ \\
\hline $\begin{array}{l}\text { "I would personally benefit from using a self-help } \\
\text { mobile app like the one being tested in this study" }\end{array}$ & $5.40(1.08)$ & $5.00(1.23)$ \\
\hline "I am interested in using a self-help mobile app" b & $5.50(1.35)$ & $5.38(1.04)$ \\
\hline
\end{tabular}

${ }^{a}$ Based on validated cutoff scores for each CCAPS subscale. ${ }^{26}$

${ }^{\mathrm{b}}$ Rated on a 7-point scale with 5 (slightly agree) or higher indicating interest in using an app. 
Table 2. Post-intervention self-report items assessing satisfaction and therapy usage factors in the SBT condition.

\begin{tabular}{|c|c|c|}
\hline Item & $M(S D)$ & $\begin{array}{l}\geq 4 \\
\text { "slightly agree" }\end{array}$ \\
\hline \multicolumn{3}{|l|}{ General Satisfaction Items } \\
\hline Overall, I was satisfied with the quality of SBT & $4.20(1.64)$ & $60 \%$ \\
\hline SBT was helpful to me. & $4.20(2.05)$ & $60 \%$ \\
\hline SBT was easy to use. & $5.00(1.23)$ & $80 \%$ \\
\hline SBT was enjoyable to use. & $4.80(1.10)$ & $80 \%$ \\
\hline I felt SBT was made for someone like me & $3.80(1.92)$ & $60 \%$ \\
\hline I would like to use SBT again in the future & $4.60(1.67)$ & $60 \%$ \\
\hline I would recommend SBT to a student struggling with a mental health problem & $4.60(1.67)$ & $80 \%$ \\
\hline \multicolumn{3}{|l|}{ Use in Therapy Items } \\
\hline I think SBT would be helpful for students waiting to receive therapy & $4.20(2.05)$ & $60 \%$ \\
\hline My counseling center should recommend SBT to students on the waiting list & $4.40(1.82)$ & $60 \%$ \\
\hline SBT helped me to get more out of therapy & $3.50(1.29)$ & $60 \%$ \\
\hline SBT increased my motivation to see a therapist & $4.00(.71)$ & $80 \%$ \\
\hline I would have preferred to see a therapist right away rather than use SBT first* & $5.20(1.10)$ & $100 \%$ \\
\hline SBT was helpful enough I didn't need to see a therapist anymore after using it & $1.80(1.10)$ & $0 \%$ \\
\hline SBT could be a good replacement for seeing a therapist for some students & $2.60(1.34)$ & $40 \%$ \\
\hline SBT would be more helpful if it was used while students actively see a therapist* & $5.00(.71)$ & $100 \%$ \\
\hline I needed more training on how to use SBT before I started using it* & $2.20(1.64)$ & $40 \%$ \\
\hline
\end{tabular}

Note: Items were rated on a 6-point scale with 4 (slightly agree) or higher indicating a positive response with the exception of reverse scored items indicated with an *. 
Table 3. Descriptive statistics for each outcome and process measure by condition and time point.

\begin{tabular}{|c|c|c|c|c|c|c|c|c|}
\hline \multirow[b]{2}{*}{ Variable } & \multicolumn{3}{|c|}{ SBT App Condition } & \multicolumn{3}{|c|}{ Control Condition } & \multicolumn{2}{|c|}{ Hedge's $g(90 \% \mathrm{CI})$} \\
\hline & $\begin{array}{l}\text { Pre } M \\
(S D)\end{array}$ & $\begin{array}{l}\text { Mid } M \\
(S D)\end{array}$ & $\begin{array}{l}\text { Post } M \\
(S D)\end{array}$ & $\begin{array}{l}\text { Pre } \bar{M} \\
(S D)\end{array}$ & $\begin{array}{l}\operatorname{Mid} M \\
(S D)\end{array}$ & $\begin{array}{l}\text { Post } M \\
(S D)\end{array}$ & $\begin{array}{l}\text { Pre-Mid SBT } \\
\text { vs Control }\end{array}$ & $\begin{array}{l}\text { Pre-Post SBT } \\
\text { vs Control }\end{array}$ \\
\hline Outcome Measures & & & & & & & & \\
\hline CCAPS-Distress & $\begin{array}{l}2.25 \\
(.32)\end{array}$ & $\begin{array}{l}1.68 \\
(.65)\end{array}$ & $\begin{array}{l}1.46 \\
(.67)\end{array}$ & $\begin{array}{l}2.04 \\
(.51)\end{array}$ & $\begin{array}{l}2.00 \\
(.74)\end{array}$ & $\begin{array}{l}1.88 \\
(.70)\end{array}$ & $\begin{array}{l}.87 * \\
(.09,1.70)\end{array}$ & $\begin{array}{l}.92 * \\
(.06,1.86)\end{array}$ \\
\hline CCAPS-Depression & $\begin{array}{l}2.48 \\
(.59)\end{array}$ & $\begin{array}{l}1.90 \\
(1.05)\end{array}$ & $\begin{array}{l}1.58 \\
(.79)\end{array}$ & $\begin{array}{l}2.04 \\
(.89)\end{array}$ & $\begin{array}{l}1.98 \\
(1.20)\end{array}$ & $\begin{array}{l}2.02 \\
(.97)\end{array}$ & $\begin{array}{l}.80^{*} \\
(.02,1.62)\end{array}$ & $\begin{array}{l}1.06^{*} \\
(.18,2.02)\end{array}$ \\
\hline CCAPS-General Anx & $\begin{array}{l}2.27 \\
(.65)\end{array}$ & $\begin{array}{l}1.56 \\
(.92)\end{array}$ & $\begin{array}{l}1.36 \\
(1.19)\end{array}$ & $\begin{array}{l}2.19 \\
(.81)\end{array}$ & $\begin{array}{l}2.35 \\
(.70)\end{array}$ & $\begin{array}{l}2.00 \\
(.87)\end{array}$ & $\begin{array}{l}1.07 * \\
(.28,1.93)\end{array}$ & $\begin{array}{l}.56 \\
(-.29,1.45)\end{array}$ \\
\hline CCAPS-Social Anx & $\begin{array}{l}2.38 \\
(.93)\end{array}$ & $\begin{array}{l}2.25 \\
(.81)\end{array}$ & $\begin{array}{l}1.70 \\
(.88)\end{array}$ & $\begin{array}{l}2.69 \\
(.86)\end{array}$ & $\begin{array}{l}2.53 \\
(1.18)\end{array}$ & $\begin{array}{l}2.70 \\
(1.02)\end{array}$ & $\begin{array}{l}.11 \\
(-.64, .89)\end{array}$ & $\begin{array}{l}.72 \\
(-.13,1.63)\end{array}$ \\
\hline CCAPS-Academic & $\begin{array}{l}2.65 \\
(.97)\end{array}$ & $\begin{array}{l}2.41 \\
(.93)\end{array}$ & $\begin{array}{l}2.46 \\
(.93)\end{array}$ & $\begin{array}{l}2.31 \\
(.98)\end{array}$ & $\begin{array}{l}2.18 \\
(1.09)\end{array}$ & $\begin{array}{l}2.03 \\
(.91)\end{array}$ & $\begin{array}{l}.27 \\
(-.49,1.04)\end{array}$ & $\begin{array}{l}.49 \\
(-.36,1.37)\end{array}$ \\
\hline CCAPS-Eating & $\begin{array}{l}1.37 \\
(1.02)\end{array}$ & $\begin{array}{l}1.25 \\
(1.14)\end{array}$ & $\begin{array}{l}1.28 \\
(1.48)\end{array}$ & $\begin{array}{l}1.15 \\
(1.39)\end{array}$ & $\begin{array}{l}1.36 \\
(1.34)\end{array}$ & $\begin{array}{l}1.73 \\
(1.25)\end{array}$ & $\begin{array}{l}.32 \\
(-, 44,1.10)\end{array}$ & $\begin{array}{l}.43 \\
(-.41,1.31)\end{array}$ \\
\hline CCAPS-Hostility & $\begin{array}{l}.77 \\
(.85)\end{array}$ & $\begin{array}{l}.44 \\
(.45)\end{array}$ & $\begin{array}{l}.31 \\
(.32)\end{array}$ & $\begin{array}{l}.47 \\
(.46)\end{array}$ & $\begin{array}{l}.56 \\
(.48)\end{array}$ & $\begin{array}{l}.50 \\
(.44)\end{array}$ & $\begin{array}{l}1.06^{*} \\
(.27,1.92)\end{array}$ & $\begin{array}{l}.79 \\
(-.06,1.71)\end{array}$ \\
\hline $\begin{array}{l}\text { MHC-Positive } \\
\text { Mental Health }\end{array}$ & $\begin{array}{l}46.20 \\
(9.17)\end{array}$ & $\begin{array}{l}40.75 \\
(8.45)\end{array}$ & $\begin{array}{l}48.17 \\
(17.22)\end{array}$ & $\begin{array}{l}45.69 \\
(10.66)\end{array}$ & $\begin{array}{l}48.00 \\
(9.96)\end{array}$ & $\begin{array}{l}49.70 \\
(11.55)\end{array}$ & $\begin{array}{l}-.40 \\
(-1.19, .36)\end{array}$ & $\begin{array}{l}.52 \\
(-.31,1.41)\end{array}$ \\
\hline Process Measures & & & & & & & & \\
\hline FFMQ-Observe & $\begin{array}{l}23.50 \\
(4.62)\end{array}$ & $\begin{array}{l}20.25 \\
(4.74)\end{array}$ & $\begin{array}{l}22.83 \\
(6.24)\end{array}$ & $\begin{array}{l}25.00 \\
(4.58)\end{array}$ & $\begin{array}{l}24.45 \\
(4.97)\end{array}$ & $\begin{array}{l}22.50 \\
(6.06)\end{array}$ & $\begin{array}{l}-.76 \\
(-1.58, .01)\end{array}$ & $\begin{array}{l}.21 \\
(-.64,1.07)\end{array}$ \\
\hline FFMQ-Describe & $\begin{array}{l}21.40 \\
(7.34)\end{array}$ & $\begin{array}{l}21.88 \\
(5.99)\end{array}$ & $\begin{array}{l}22.00 \\
(10.20)\end{array}$ & $\begin{array}{l}22.38 \\
(6.49)\end{array}$ & $\begin{array}{l}23.18 \\
(5.64)\end{array}$ & $\begin{array}{l}24.00 \\
(6.78)\end{array}$ & $\begin{array}{l}.62 \\
(-.14,1.43)\end{array}$ & $\begin{array}{l}.69 \\
(-.16,1.59)\end{array}$ \\
\hline FFMQ-Act Aware & $\begin{array}{l}18.30 \\
(2.16)\end{array}$ & $\begin{array}{l}22.13 \\
(4.64)\end{array}$ & $\begin{array}{l}22.50 \\
(5.79)\end{array}$ & $\begin{array}{l}20.00 \\
(5.23)\end{array}$ & $\begin{array}{l}19.55 \\
(4.72)\end{array}$ & $\begin{array}{l}20.80 \\
(4.21)\end{array}$ & $\begin{array}{l}1.06^{*} \\
(.27,1.91)\end{array}$ & $\begin{array}{l}.68 \\
(-.17,1.58)\end{array}$ \\
\hline FFMQ-Nonjudge & $\begin{array}{l}17.70 \\
(5.93)\end{array}$ & $\begin{array}{l}22.75 \\
(8.41)\end{array}$ & $\begin{array}{l}25.33 \\
(6.19)\end{array}$ & $\begin{array}{l}19.46 \\
(5.55)\end{array}$ & $\begin{array}{l}21.81 \\
(8.12)\end{array}$ & $\begin{array}{l}21.90 \\
(8.66)\end{array}$ & $\begin{array}{l}.42 \\
(-.34,1.21)\end{array}$ & $\begin{array}{l}.56 \\
(-.28,1.46)\end{array}$ \\
\hline FFMQ-Nonreact & $\begin{array}{l}19.10 \\
(3.07)\end{array}$ & $\begin{array}{l}17.63 \\
(2.56)\end{array}$ & $\begin{array}{l}17.42 \\
(3.75)\end{array}$ & $\begin{array}{l}18.23 \\
(3.92)\end{array}$ & $\begin{array}{l}18.82 \\
(3.74)\end{array}$ & $\begin{array}{l}18.50 \\
(40.06)\end{array}$ & $\begin{array}{l}-.43 \\
(-1.22, .33)\end{array}$ & $\begin{array}{l}-.31 \\
(-1.17, .54)\end{array}$ \\
\hline VQ-Obstruction & $\begin{array}{l}26.20 \\
(3.12)\end{array}$ & $\begin{array}{l}25.13 \\
(4.70)\end{array}$ & $\begin{array}{l}20.40 \\
(5.68)\end{array}$ & $\begin{array}{l}22.85 \\
(4.65)\end{array}$ & $\begin{array}{l}23.36 \\
(4.70)\end{array}$ & $\begin{array}{l}21.00 \\
(5.83)\end{array}$ & $\begin{array}{l}.40 \\
(-.36,1.18)\end{array}$ & $\begin{array}{l}.47 \\
(-.42,1.41)\end{array}$ \\
\hline VQ-Progress & $\begin{array}{l}18.10 \\
(3.60)\end{array}$ & $\begin{array}{l}19.00 \\
(3.66) \\
\end{array}$ & $\begin{array}{l}24.00 \\
(4.24) \\
\end{array}$ & $\begin{array}{l}17.85 \\
(3.63) \\
\end{array}$ & $\begin{array}{l}21.18 \\
(5.00)\end{array}$ & $\begin{array}{l}20.40 \\
(6.24) \\
\end{array}$ & $\begin{array}{l}-.61 \\
(-1.42, .15) \\
\end{array}$ & $\begin{array}{l}.85 \\
(-.06,1.83) \\
\end{array}$ \\
\hline
\end{tabular}

Scale ranges: CCAPS subscales $=0-4$, MHC $=14-84$, FFMQ Observe, Describe, Act with Awareness, Nonjudge $=8-40$, FFMQ Nonreact $=7-42$. VQ subscales $=5-35$. Effect sizes calculated with available data using listwise deletion. * indicates $90 \%$ CI does not contain 0. Positive effect sizes $=$ greater improvement in SBT vs. control. 


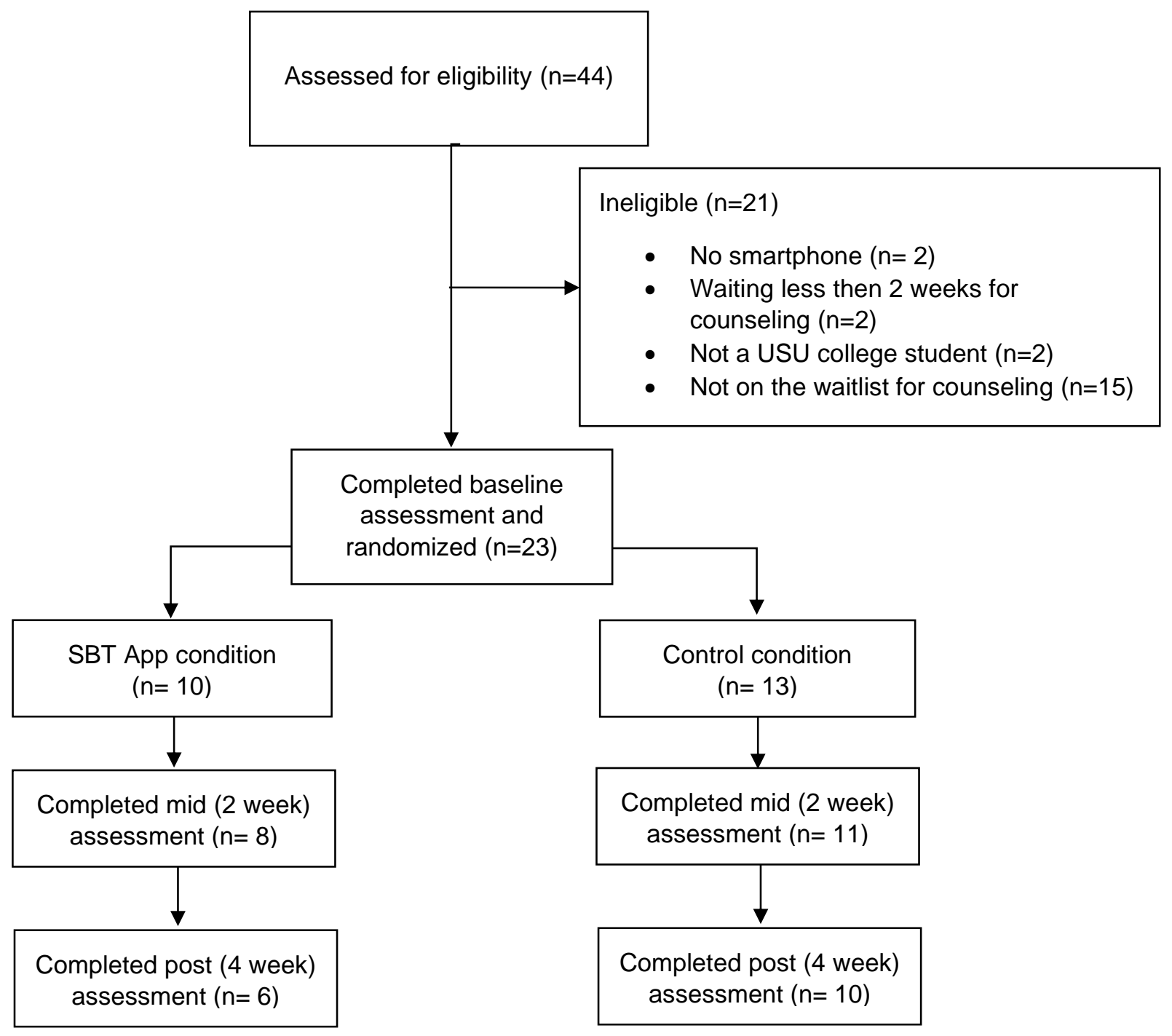

Figure 1. Participant flow diagram. 